2014-08

\title{
When do I wear me out? Mental simulation and the diminution of self-control.
}

\section{Macrae, CN}

http://hdl.handle.net/10026.1/15536

\subsection{7/a0036100}

J Exp Psychol Gen

All content in PEARL is protected by copyright law. Author manuscripts are made available in accordance with publisher policies. Please cite only the published version using the details provided on the item record or document. In the absence of an open licence (e.g. Creative Commons), permissions for further reuse of content should be sought from the publisher or author. 
IN PRESS - Journal of Experimental Psychology: General

Running Head: Simulated Self-Control

\section{When Do I Wear Me Out?}

\section{Mental Simulation and the Diminution of Self-Control}

C. Neil Macrae, Brittany M. Christian, Marius Golubickis, Magdalene Karanasiou, Lenka Troksiarova, Diana L. McNamara, Lynden K. Miles

University of Aberdeen, Scotland

WORD COUNT: 6056

Address Correspondence To:

Neil Macrae

School of Psychology

University of Aberdeen

King's College

Aberdeen AB24 3FX

Scotland, UK

Email: c.n.macrae@abdn.ac.uk 


\begin{abstract}
Exerting self-control can diminish people's capacity to engage in subsequent acts of behavioral regulation, a phenomenon termed ego depletion. But what of imaginary regulatory experiences does simulated restraint elicit comparable lapses in self-control? Here we demonstrate such effects under theoretically tractable imagery conditions. Across three experiments, temporal, structural and spatial components of mental simulation were observed to drive the efficacy of imaginary selfcontrol. In Experiment 1, lapses in restraint (i.e., financial impulsivity) were more pronounced when imaginary regulation (i.e., dietary restraint) focused on an event in the near than distant future. In Experiment 2, comparable effects (i.e., increased stereotyping) emerged when simulated self-control (i.e., emotional suppression) was imagined from a first-person (cf. third-person) visual perspective. In Experiment 3, restraint was diminished (i.e., increased risk taking) when selfregulation (i.e., action control) centered on an event at a near than distant location. These findings further delineate the conditions under which mental simulation impacts core aspects of socialcognitive functioning.
\end{abstract}

Keywords: mental simulation, self-control, temporal construal, visual perspective 
When Do I Wear Me Out?

Mental Simulation and the Diminution of Self-Control

"You have power over your mind — not outside events. Realize this and you will find strength."

Marcus Aurelius, Meditations

Recent estimates suggest that people spend up to half their waking lives imagining (i.e., simulating) rather than directly apprehending the world around them (Killingworth \& Gilbert, 2010; Smallwood \& Schooler, 2006). They do so for good reason, however. Mental simulation ensures that behavior is optimized to meet the complex demands of daily living (Boyer, 2008; Gilbert \& Wilson, 2007; Suddendorf \& Corballis, 2007; Wilson \& Gilbert, 2003). For example, before proposing marriage, assembling a bookcase or attempting a challenging violin solo, prior mental preparation can be an invaluable tactic. Guided by the mutual influence of semantic and episodic knowledge (Addis, Wong, \& Schacter, 2007; Buckner \& Carroll, 2007; Schacter, Addis, \& Buckner, 2007; Szpunar, 2010), future previews provide a window into the character and potential consequences of yet-to-be-experienced events (Gilbert \& Wilson, 2007; Suddendorf \& Corballis, 2007). In so doing, they serve a pivotal function in shaping future conduct.

The benefits of mental simulation derive from the overlapping neurocognitive operations that support imagination and perception/action (e.g., Ganis, Thompson, \& Kosslyn, 2004; Jeannerod, 2001; Fadiga \& Craighero, 2004; Grèzes \& Decety, 2001; Kosslyn, Ganis, \& Thompson, 2001; Moulton \& Kosslyn, 2009). Retaining essential properties of the events they represent, mental simulations (e.g., riding a bicycle) trigger the same sensorimotor processes that operate during the actual execution of the imagined activity. Embodied in this way (e.g., Barsalou, 1999; Jeannerod, 1994; Moulton \& Kosslyn, 2009; Wilson, 2002), thinking can be characterized as a functional antecedent of doing. Over the years, the advantages of mental practice have been well documented (Grouios, 1992; Moulton \& Kosslyn, 2009). Imagining an activity not only increases 
the likelihood that it will occur (Anderson, 1983), it also enhances task performance when the behavior is executed (Taylor, Pham, Rivkin, \& Armor, 1998), an effect that has been reported in an impressive (and ever expanding) range of artistic, musical and sporting pursuits (e.g., Brouziyne \& Molinaro, 2005; Caliari, 2008; Prather, 1973; Theiler \& Lippman, 1995; Woolfolk, Parrish, \& Murphy, 1985). Put simply, mental preparation is a reliable performance-enhancing activity.

Planning for action, of course, comprises but a single strand of mentation. Of comparable importance is the opposite ability, preparing for inaction. Whether one's goal is to avoid gorging on donuts, insulting a relative or getting flustered during a formal presentation, mental simulation can be deployed in an attempt to circumvent the expression of inappropriate outputs (Suddendorf \& Corballis, 2007). That is, just as self-regulation can be implemented in real-time to prevent an unwanted outcome (Wegner, 1994), so too it can be triggered offline (i.e., imaginary self-control) prior to the occurrence of an event (Wilson, 2002). This capacity to simulate self-control raises an interesting issue. Might imagined restraint mimic the reported consequences of actual behavioral control? A common finding in the literature is that self-regulatory success begets self-regulatory failure - specifically, periods of successful restraint can be followed by lapses in regulatory processing (see Hagger, Wood, Stiff, \& Chatzisarantis, 2010; Muravan \& Baumeister, 2000). But do similar effects arise when self-control is imaginary rather than real? Moreover, are some imagery conditions more likely than others to lead self-regulation awry? We explored these questions in the current investigation.

\section{Simulating Self-Control}

A prominent theoretical account of self-control contends that resisting temptation makes demands on a limited but renewable regulatory resource (i.e., ego depletion effect, Baumeister, Vohs, \& Tice, 2007; Heatherton \& Vohs, 1998; Muraven \& Baumeister, 2000; but see Inzlicht \& Schmeichel, 2012; Kurzban, Duckworth, Kable, \& Myers, 2013). As a result, until regulatory capacity is restored, exerting restraint in one setting (e.g., not eating chocolate) can impair selfregulation in another (e.g., persistence in solving a frustrating puzzle), even when the to-be- 
controlled activities are quite distinct (Baumeister, Bratslavsky, Muraven, \& Tice, 1998). While existing research has yet to consider the consequences of simulated self-restraint, effects compatible with ego depletion have been reported in related work investigating vicarious self-control. According to simulation theory (see Goldman, 2006), person understanding is grounded in the ability to recreate the mental and physical states of others (e.g., 'what you feel, I feel'). As such, perceiving (or imagining) other people's actions is accompanied by much of the same neural activity that would occur if one performed the activity oneself (Decety \& Grèzes, 2006; Gallese, Keysers, \& Rizzolati, 2004; Ruby \& Decety, 2001). This viewpoint has interesting implications for self-regulatory processing. If imagining another person's inaction triggers one's own self-regulatory experiences (Holmes \& Matthews, 2010; McIsaac \& Eich, 2004; Schacter et al., 2007; Wilson, 2002), then vicarious ego depletion (i.e., impaired regulatory processing) may arise.

To explore this possibility, Ackerman, Goldstein, Shapiro and Bargh (2009) presented participants with a story in which a hungry waiter (or waitress) was unable to eat any of the culinary delights that were available at work for fear of dismissal. Critically, some participants were instructed to place themselves in the shoes of the employee and imagine the difficulties involved when resisting temptation (i.e., perspective-takers), others simply to read the story. Afterwards, all participants completed a task in which they reported how much they would be prepared to pay for several consumer goods (e.g., watch, car). In such a price-assignment task, impaired self-control is indexed by a willingness to spend excessively on the items (Vohs \& Faber, 2007). Supporting the hypothesis that vicarious self-control impairs regulatory capacity, perspective-takers were prepared to spend more $(\sim 6000)$ for the items than their counterparts in the read-only condition. What this therefore suggests is that imaginary control can impact self-regulatory outcomes, at least when one is directed to adopt the perspective of others (Ackerman et al., 2009).

Perspective-taking aside, what of situations that capture the essence of self-control — the regulation of one's own behaviour. Does imaginary self-restraint impede subsequent regulatory outcomes? Not only do we expect this to be the case, but also that effects of this kind may be most 
pronounced under theoretically important imagery conditions. Underlying this assumption is the observation that differences in the temporal, spatial and structural components of simulated events exert considerable influence on the behavioral consequences of prospection (see Libby \& Eibach, 2011; Trope \& Liberman, 2003, 2010). Consistent with the tenets of action identification theory (Vallacher \& Wegner, 1985), future events can be characterized in either a super- or subordinate manner. Whereas superordinate (i.e., high-level) construal comprises abstract, de-contextualized representations that capture the gist or meaning of a prospective experience, subordinate (i.e., lowlevel) construal conveys concrete, detail-rich representations of an event (Gilbert \& Wilson, 2007; Szpunar, 2010). Thus, while superordinate representations center on the overarching purpose of an action, subordinate characterizations focus instead on the specific means though which a future activity (or goal) can be realized (Christian, Miles, Fung, Best, \& Macrae, 2013).

Differences in the representation (i.e., abstract vs. concrete) of simulated events have important implications for the embodied reactions that accompany off-line cognition (Barsalou, 1999; Wilson, 2002). For example, neuroimaging investigations have revealed greater activity in motor and sensorimotor regions (i.e., sensorimotor re-enactments) when actions are imagined from a subordinate than superordinate perspective (Jackson, Meltzoff, \& Decety, 2006; Lorey et al., 2009; Ruby \& Decety, 2001). Similarly, the contents of mental simulations comprise more information about bodily sensations, affective reactions and psychological states as the specificity of event construal increases (Holmes \& Mathews, 2010; McIssac \& Eich, 2002, 2004). Of relevance here, these findings potentially inform both the process and consequences of simulated self-control. Specifically, if sensorimotor re-enactments are amplified when events are simulated in a subordinate manner (i.e., low-level construal), then as activities (e.g., resisting a bowl of ice cream) increase in representational specificity so too should the putative demands of imaginary selfrestraint. By extension, effects indicative of self-regulatory impairment (i.e., ego depletion) should be more pronounced when prior periods of simulated restraint operate on concrete rather than abstract mental representations of events. Using manipulations acknowledged to vary the specificity 
of event construal (i.e., temporal distance, visual perspective, spatial distance; see Libby \& Eibach, 2011, Trope \& Liberman, 2010), we explored this prediction in three experiments.

\section{Experiment 1}

\section{Temporal Distance and Simulated Self-Control}

Confirmed by an extensive literature, construal level theory (CLT) contends that representations increase in abstraction as mental simulations shift from imminent events to those in the distant future (Liberman \& Trope, 2008; Trope \& Liberman, 2003, 2010). For example, a dinner party scheduled to take place tomorrow evening will be characterized quite differently (i.e., lowlevel construal: purchasing lemongrass, squeezing limes, setting the table) than the identical event in a year's time (i.e., high-level construal: interacting with friends, enjoying Asian cuisine). Representations tend to shift from an analysis of the steps necessary to achieve a desired outcome (i.e., means to an end) to a consideration of the outcome itself (i.e., end) as to-be-enacted events increase in temporal distance (Liberman \& Trope, 2008). These differences in construal have obvious implications for simulated self-control. Given that concrete (i.e., low-level) event representations amplify embodied simulations (Jackson et al., 2006; Lorey et al., 2009; Ruby \& Decety, 2001), imaginary control should be more demanding when restraint is required for an activity that is scheduled to occur in the near than distant future (Thomas \& Tsai, 2012).

To explore this issue, participants were required to imagine resisting the temptation to consume tasty snacks at a party in either the near or distant future. Afterwards, in an ostensibly separate task, they gave estimates of how much they would be willing to spend on a range of consumer products (Ackerman et al., 2009). As the availability of self-regulatory resources predicts financial restraint (i.e., resource depleted people spend excessively, see Vohs \& Faber, 2007), participants were expected to spend more money when they had resisted temptation in the near than distant future. 


\section{Method}

\section{Participants and Design}

Forty female undergraduates at the University of Aberdeen took part in the research in exchange for course credit. ${ }^{1}$ The experiment had a single factor (Temporal Distance: near or far) between-subjects design and was reviewed and approved by the School of Psychology, University of Aberdeen ethics committee.

\section{Materials and Procedure}

Participants arrived at the laboratory individually and were greeted by a female experimenter who explained that the research involved the performance of two separate tasks (i.e., guided-imagery task \& shopping task). Prior to the imagery task, participants were asked to specify a party food (sweet or savoury) that they find completely irresistible. This personalized item served as the to-be-resisted target during a guided imagery exercise in which participants were instructed to imagine attending a friend's party that was scheduled to take place either tomorrow evening (i.e., near future) or in 3 years' time (i.e., far future). Participants were also told that they had decided not to eat anything at the party, even though their favorite snack was readily available and offered repeatedly by the host. During the imagery that followed, participants were instructed to visualize being offered their beloved snack numerous times, but to resist temptation on each occasion. Participants were blindfolded to enhance the vividness of their imagery and given 2 minutes to simulate the event. They then completed the Brief Mood Introspection Scale (BMIS; Mayer \& Gaschke, 1988), a measure commonly used in work exploring self-regulatory depletion (e.g., Ackerman et al., 2009; Baumeister et al., 1998).

Next, participants were given a standard price-assignment task (see Vohs \& Faber, 2007). Ten color photographs of mid-priced products were presented (e.g., camera, refrigerator, ring,

\footnotetext{
${ }^{1}$ Sample sizes in the current research were based on an a priori rule-of-thumb of 20 participants per cell for Experiments 1 and 2, and 30 participants per cell for Experiment 3 (factorial design). Obtained power within each study was $83 \%, 65 \%$ and $76 \%$ respectively, meaning that across the 3 studies average power (i.e., $75 \%$ ) approached $80 \%$.
} 
designer shoes) and participants listed (in £s) how much they would be prepared to pay for each item. Based on related work (Ackerman et al., 2009; Vohs \& Faber, 2007), the products selected were ones for which participants lacked precise knowledge of the actual costs involved, thereby enabling sufficient variance in their price estimates. On completion of the task, participants were debriefed, thanked and dismissed.

\section{Results}

Following previous research (Vohs \& Faber, 2007), a composite pricing index was calculated by averaging the amounts that participants were willing to spend on the 10 items. A $t$-test on this index revealed an effect of Temporal Distance, $t(38)=2.96, p=.005$, Cohen's $d=0.96$, such that participants were prepared to spend more on the products when simulated self-control focused on a party that was scheduled to take place in the near $(M=£ 1440, S E=£ 305)$ than far $(M$ $=£ 489, S E=£ 101)$ future (see Figure 1). No difference in mood was observed as a function of the temporal focus of simulated self-control $(t<1)$.

\section{Discussion}

The current findings support the contention that temporal aspects of mental construal impact the consequences of simulated self-control. Compared to participants who exercised imaginary culinary restraint at a party in three years' time, those who resisted identical temptation in the immediate future were prepared to pay considerably more (i.e., £1135) for a collection of products (see also Ackerman et al., 2009; Vohs \& Faber, 2007). What this suggests is that simulating restraint triggered experiences associated with mental operations that support successful self-control (Barsalou, 1999; Wilson, 2002), which in turn influenced financial impulsivity. Critically, however, this effect was moderated by the anticipated date of the imaginary event (Liberman \& Trope, 2008; Trope \& Liberman, 2003, 2010). While noteworthy, temporal distance is likely to be but a single facet of mental construal that impacts self-regulatory processing. Accordingly, to establish the generality of the effects observed in Experiment 1, in our next study we manipulated another factor 
that is acknowledged to moderate the representational status of simulated events - the visual perspective from which an episode is imagined (Libby \& Eibach, 2011). Specifically, we explored the extent to which simulated self-control shapes people's propensity to stereotype others.

\section{Experiment 2}

\section{Visual Perspective and Simulated Self Control}

When imagining an event (e.g., making a cup of coffee), people can adopt either a field (i.e., first-person) or observer (i.e., third-person) spatial visual perspective (Avraamides \& Kelly, 2008). From a first-person perspective, people experience events through their own eyes (i.e., actor-focus), as if they are looking outward on the world. In contrast, from a third-person viewpoint they see themselves as actors embedded in an event (i.e., observer-focus), as if from an external position (Libby \& Eibach, 2011). These contrasting vantage points exert a direct influence on the specificity of event construal. Compared to third-person representations of events, first-person simulations comprise greater detail (McIssac \& Eich, 2002, 2004) and trigger elevated activity in modalityspecific systems (Jackson et al., 2006; Lorey et al., 2009). In other words, first-person simulations are more embodied than third-person versions of the same event (Lorey et al., 2009; Macrae, Sunder Raj, Best, Christian, \& Miles, 2013; Miles, Christian, Masilamani, Volpi, \& Macrae, in press). What this suggests is that imaginary control should be more demanding when self-restraint is simulated from a first- than third-person perspective.

To explore this prediction, during an imaginary social interaction participants were required to resist the temptation to laugh at a friend's unfortunate mishap (i.e., emotional control, see Baumeister et al., 1998). Critically, the event was simulated from either a first- or third-person visual perspective. Afterwards, in an ostensibly separate task, participants were asked to describe a typical day in the life of a target depicted in a photograph (Macrae, Bodenhausen, Milne, \& Jetten, 1994). As the availability of regulatory resources has been shown to impact person perception (i.e., regulatory impairment increases stereotyping, see Gordijn, Hindriks, Koomen, Dijksterhuis, \& Van 
Knippenberg, 2004; Govorun \& Payne, 2006, Muraven, 2008), descriptions of the target were expected to be more stereotypic when a first-person (cf. third-person) perspective was adopted during simulated self-control.

\section{Method}

\section{Participants and Design}

Forty undergraduates (16 males) at the University of Aberdeen took part in the research in exchange for course credit. The experiment had a single factor (Visual Perspective: first or third) between-subjects design and was reviewed and approved by the School of Psychology, University of Aberdeen ethics committee.

\section{Materials and Procedure}

Participants arrived at the laboratory individually and were greeted by a female experimenter who explained that the session involved the performance of two separate tasks (i.e., guided-imagery task \& person-perception task). The first task consisted of a guided mental-imagery exercise (i.e., ego depletion task) in which participants were instructed to imagine a social interaction with their best friend and to control their emotions and facial expressions during the exchange. They were told that the interaction was taking place outside a coffee shop in town and the topic of conversation was their mutual plans for the upcoming weekend. Unbeknownst to the best friend, prior to the interaction bird poo had landed on her/his head and was clearly visible to all. Participants were instructed not to laugh, smile or tell their friend about the unfortunate mishap at any time during the interaction. Prior to the imagery, participants were instructed about the visual perspective they were required to adopt (Macrae et al., 2013). Those in the first-person condition were told: "When you imagine the event, please picture it from a first-person perspective. Visualize the event from your own viewpoint — that is, see the event through your own eyes." Alternatively, participants in the third-person condition were instructed: "When you imagine the event, please picture it from a third-person perspective. Visualize the event as if you yourself were an outside 
observer — that is, see yourself and the surroundings." Participants were then blindfolded to enhance the vividness of their imagery and given 60 seconds to visualize the event. Following the guided imagery, participants reported the visual perspective they had adopted (i.e., first vs. third) during the task and completed the BMIS. In addition, they estimated the difficulty they had experienced generating a mental image by placing a mark on an analogue scale $(14 \mathrm{~cm}$ line $)$ anchored with appropriate endpoints (i.e., not at all difficult/very difficult).

Next, participants completed an ostensibly unrelated person-perception task. The experimenter explained that she was interested in people's ability to construct life event details from a photograph. Participants were then shown a color photograph of an unfamiliar blond, female model and instructed to compose a brief passage (on the paper provided) describing a typical day in her life (see Macrae et al., 1994). They were given 5 minutes to complete this task. Of interest was the extent to which stereotypes were used to characterize the target and her lifestyle. Coders were informed to look for material (e.g., personality traits, hobbies, activities) that pertained to stereotypes of women (e.g., passive, emotional, gossipy) and/or blonds (e.g., shallow, trendy, obsessed by appearance) when reviewing the passages. On completion of the task, participants were debriefed, thanked and dismissed.

\section{Results}

Data from 3 participants (all males) were excluded from analysis as they reported simulating the event from the incorrect perspective. Following previous research (Macrae et al., 1994), two independent coders ( 1 female), who were blind to experimental condition and the purpose of the investigation, rated the passages for stereotypical content (i.e., 7-point rating scale: $1=$ not at all stereotypic; 7 highly stereotypic). Given the high level of agreement in their ratings, $r(35)=.78, p<$ .0001 , scores were averaged and a single measure of stereotypicality was calculated for each passage. A $t$-test on these values revealed an effect of Visual Perspective, $t(35)=2.34, p=.024$, Cohen's $d=0.79$, such that descriptions were more stereotypic when self-control was simulated from a first- $(M=4.72, S E=0.35)$ than third-person $(M=3.66, S E=0.29)$ perspective (see Figure 
2). No differences in mood or difficulty generating mental images were observed as a function of the visual perspective adopted during simulated self-control (both $t \mathrm{~s}<1$ ).

\section{Discussion}

These findings corroborate the contention that simulated restraint can impact subsequent acts of self-control (Ackerman et al., 2009). Category-based descriptions of a target were moderated by the structural components of prior mental imagery, such that stereotyping was exacerbated when self-control (i.e., not laughing at a friend's mishap) was imagined from a first-person (cf. thirdperson) vantage point. Collectively, Experiments 1 and 2 confirm that imaginary restraint can trigger lapses in self-control (i.e., ego depletion) suggestive of impaired regulatory processing (Hagger et al., 2010; Muraven \& Baumeister, 2000). Importantly, however, these effects were most pronounced under specific imagery conditions, notably task contexts in which concrete event representations were generated (Libby \& Eibach, 2011; Trope \& Liberman, 2003, 2010).

Notwithstanding the results observed in Experiments 1 and 2, it is possible that a factor other than simulated restraint may have impaired regulatory processing. Elsewhere, it has been established that abstract (i.e., high-level construal) thinking is promoted both by reflection on temporally distant (cf. temporally close) events (e.g., Liberman \& Trope, 2008) and field (cf. observer) imagery (Libby, Shaeffer, \& Eibach, 2009). Moreover, high-level construal (cf. low-level construal) has been shown to facilitate self-control (Fujita, Trope, Liberman, \& Levin-Sagi, 2006). Taken together, these findings suggest that a construal-level explanation (i.e., priming concrete construal) could account for the current findings (Trope \& Liberman, 2003, 2010). Specifically, low-level construal (i.e., thinking about events in the near future, adopting a first-person visual perspective) may impair subsequent regulatory processing. To tease apart these competing possibilities (i.e., simulated self-control vs. level of construal), we conducted a third study that included both imagined restraint (cf. Expts $1 \& 2$ ) and a no-depletion, control condition in which only event specificity (i.e., abstract vs. concrete) was manipulated. 


\section{Experiment 3}

\section{Spatial Distance and Simulated Self-Control}

As described by CLT, representations increase in abstraction as mental simulations shift from events in near to distant locations (Liberman \& Trope, 2008; Trope \& Liberman, 2003, 2010). For example, Fujita, Henderson, Eng, Trope and Liberman (2006) reported that whereas imagined behaviors (e.g., locking a door) at distant locales focus on the general purpose of an action (e.g., 'securing the house'), identical acts at near locations emphasise the means through which the action can be achieved (e.g., 'putting the key in the lock'). In other words, simulated experiences in proximate settings trigger concrete (i.e., low-level) construal (see Henderson, Wakslak, Fujita, \& Rohrbach, 2011). Given therefore that concrete event representations amplify embodied simulations (Jackson et al., 2006; Lorey et al., 2009; Macrae et al., 2013; Miles et al., 2013; Ruby \& Decety, 2001), much like temporal distance (e.g., Expt 1), simulated self-control should be more demanding when restraint is required for an activity that occurs at a near than distant physical location (Henderson et al., 2011).

To explore this issue, participants were required to imagine walking speedily down the sidewalk of the main street in either a near or distant city. Critically, some participants were instructed to avoid stepping on any of the cracks between the paving stones (i.e., action control) during the imaginary episode, ${ }^{2}$ while others were given no such instruction (i.e., no depletion, control condition). Afterwards, in an ostensibly separate task, participants reported the extent to which they were prepared to engage in sensation seeking, a primary and prominent determinant of risk taking (Zuckerman, 1971; Fischer, Guter, \& Frey, 2008). Elsewhere, research has revealed that ego depletion promotes both people's inclination to take risks and their actual risk-taking behavior (Fischer, Kastenmüller, \& Asal, 2012; Freeman \& Muraven, 2010). If, therefore, simulated selfcontrol is critical for the emergence of the current effects, thrill seeking should only be elevated

\footnotetext{
${ }^{2}$ Avoiding walking on the cracks between paving stones is a common superstitious behavior among children in many nations and often continues into adult life (Vyse, 2000). Believed to bring bad luck, it is reflected in the rhyme: "Step on a crack, you'll break your mother's back."
} 
when imaginary restraint is exercised at a near compared to distant location, no comparable difference should emerge in the control (i.e., no depletion) condition.

\section{Method}

\section{Participants and Design}

One hundred and twenty undergraduates (30 males) at the University of Aberdeen took part in the research. The experiment had a 2 (Instruction: imagined restraint or control) X 2 (Location: near or distant) between-subjects design and was reviewed and approved by the School of Psychology, University of Aberdeen ethics committee.

\section{Materials and Procedure}

Participants arrived at the laboratory individually and were greeted by a male or female experimenter who explained that the research involved the performance of two separate tasks (i.e., guided-imagery task \& lifestyle questionnaire). During the guided imagery, participants were instructed to imagine walking speedily down the sidewalk of the main city street either in Aberdeen, Scotland (i.e., near condition) or Auckland, New Zealand (i.e., distant condition). Prior to this task, participants in the simulated self-control (i.e., ego depletion) condition were told to try not to step on any of the cracks between the paving stones as they walked down the sidewalk; those in the control condition were given no such instruction. Participants were given 30 seconds to simulate the event during which their eyes were closed to enhance the imaginary experience. As previously, following the guided imagery participants' mood was assessed using the BMIS.

To assess risk-taking, participants completed the Thrill and Adventure Seeking component of the Sensation Seeking Scale (SSS, Zuckerman, 1971). This instrument comprises 10 forcedchoice items that probe people's inclination to perform risky actions (e.g., A. "I would like to try parachute jumping," or B. "I would never want to try jumping out of a plane with or without a 
parachute") and is a valid and reliable method for assessing sensation seeking. On completion of the questionnaire, participants were debriefed, thanked and dismissed.

\section{Results}

Participants' thrill seeking scores (range: 0-10) were calculated and submitted to a 2 (Instruction: imagined restraint or control) x 2 (Location: near or distant) between-subjects analysis of variance (ANOVA) which yielded only a significant Instruction $\mathrm{x}$ Location interaction, $F(1,116)$ $=4.20, p=.04, \eta_{\mathrm{p}}{ }^{2}=.04$, see Figure 3. Post-hoc $t$-tests confirmed that thrill seeking was elevated when participants imagined avoiding stepping on cracks while walking down the sidewalk in Aberdeen $(M=7.23, S E=0.48)$ compared to Auckland $(M=5.57, S E=0.39), t(58)=2.68, p=$ $.013, d=0.70)$. Importantly, no such effect emerged in the control condition when participants simply imagined walking down the sidewalk in the near $(M=5.70, S E=0.48)$ or $\operatorname{distant}(M=6.10$, $S E=0.52)$ location, $t(58)<1, n s$. No differences in mood were observed as a function of the experimental manipulations (all $F^{\prime} \mathrm{s}<1$ ).

\section{Discussion}

These findings confirm that simulated self-control is essential to the generation of the current effects. Only when participants were required to regulate their behavior did effects indicative of ego depletion (i.e., increased thrill seeking) emerge (Fischer et al., 2012. Contrary to a construal-level account (Fujita et al., 2006; Trope \& Liberman, 2003, 2010) equivalent effects failed to emerge in the control condition when only event specificity was manipulated. Extending the results reported in Experiments 1 and 2, these findings provide further evidence that, under theoretically important imagery conditions, simulated restraint can impact subsequent selfregulatory outcomes. 


\section{General Discussion}

A basic and indispensable capacity of the human mind is the ability to imagine external realities (Gilbert \& Wilson, 2007; Suddendorf \& Corballis, 2007). Through the activation of the sensorimotor operations that support perception/action (Decety \& Grèzes, 2006), mental simulation serves as a valuable precursor to doing. In the current inquiry, we explored the possibility that imagination may also service the complementary objective of not doing (i.e., inaction) and revealed effects indicative of ego depletion — namely, impaired regulatory functioning following the prior expression of self-control (see Hagger et al., 2010; Muravan \& Baumeister, 2000). These effects, moreover, were observed across different self-control contexts (i.e., E1, culinary temptation; E2, emotion suppression; E3, action control), measures of behavioral restraint (i.e., E1, financial impulsivity; E2, stereotyping; E3, thrill seeking), and were moderated by temporal, structural and spatial aspects of mental simulation (Libby \& Eibach, 2011; Trope \& Liberman, 2003, 2010).

\section{Offline Cognition: Event Specificity Matters}

Extending prior research, the current findings support the contention that imagined selfcontrol impacts the efficacy of subsequent regulatory processing (Ackerman et al., 2009). Critically, however, self-regulatory impairments (i.e., ego depletion) were most pronounced when mental simulation triggered the generation of concrete event representations. This latter demonstration is noteworthy for a number of reasons. In particular, it identifies representational specificity as an essential ingredient of offline cognition (Macrae et al., 2013; Miles et al., in press). A common criticism of research on embodiment is that limited consideration is given to the precise conditions under which simulated events influence behavior (Landua, Meier, \& Keefer, 2010; Meier, Schnall, Schwarz, \& Bargh, 2012). Here we identified three such precipitating contexts. When imagined events were slated to take place in the immediate future, at a nearby location, and were generated from a first-person visual perspective (Libby \& Eibach, 2011; Trope \& Liberman, 2003, 2010) mental simulation exerted the greatest impact on people's behavior. As such, these findings 
substantiate the viewpoint that, during mental simulation, activity in modality-specific systems is moderated by a host of endogenous and exogenous factors (Glenberg, 2010; Landua et al., 2010; Meier et al., 2012). In the current investigation, for example, embodied effects were amplified when mental simulation best captured the phenomenological characteristics of physical reality (i.e., firstperson visual perspective) and focused on an impending (self-regulatory) action at a proximate location.

The demonstration that core aspects of mental simulation moderate embodied cognition sits comfortably with theoretical accounts of how the self-concept shapes social-cognitive functioning (Conway, 2010; Conway \& Pleydell-Pearce, 2000; Wheeler, DeMarree, \& Petty, 2007). According to Conway and Pleydell-Pearce (2000), the working self comprises a hierarchy of goal states that drive behavior from one moment to the next. How perception and imagination steer behavior is a function of the manner in which stimuli (e.g., sensations, ideas) make contact with (and in turn modify/update) the working self. What the current results suggest is that, during mental simulation, the working self is moulded by the specificity of simulated events (Libby \& Eibach, 2011; Trope \& Liberman, 2003, 2010). When to-be-executed activities are imagined from the vantage point that characterizes veridical action (i.e., first-person visual perspective) or are actionable because of their temporal or spatial proximity (i.e., take place in the near future or at a nearby location), the working self is grounded in sensorimotor re-enactments that approximate more closely with actual experience (Macrae et al., 2013; Miles et al., in press). In other words, embodied cognition is sensitive to the self-relevance of mentally simulated behavior (Conway, 2010; Gallese, 2005; Jeannerod, 1994).

\section{Exerting Self-Control: Unwilling or Unable?}

While an extensive literature has documented the behavioral costs associated with prior acts of self-control (i.e., diminished self-regulatory capacity, see Hagger et al., 2010), doubts have recently been cast over the claim that this effect (i.e., ego depletion) reflects the diminution of a finite physical resource. Under scrutiny, a range of findings cannot be accommodated within a strict 
capacity model of self-control (see Inzlicht \& Schmeichel, 2012; Kurzban et al., 2013). A resourcebased account of self-regulation faces similar explanatory challenges when restraint is entirely imaginary, as is the case in the current investigation and earlier work by Ackerman and colleagues (2009). ${ }^{3}$ How can imagination deplete a physical resource?

Following others, we suspect that a motivational approach may best fit the available data. That is, after exerting self-control, people may be unwilling rather than unable to exercise additional restraint. When confronted with goal-relevant actions of equivalent utility, people routinely select the path (i.e., activity) of least resistance (Solomon, 1948), thereby avoiding expending effort (i.e., work). Of theoretical relevance to the current investigation, this desire to avoid unnecessary or unpleasant labor comprises a central tenet of non-resource based accounts of self-control (e.g., Motivation/Attention Model, see Inzlicht \& Schmeichel, 2012, Inzlicht, Schmeichel, \& Macrae, in press; Labor/Leisure Tradeoff Model, see Kool \& Botvinick, in press; Opportunity Cost Model, see Kurzban et al., 2013). Although differing in several respects these models advance a common position, when people are required to exercise restraint on sequential tasks (i.e., the typical ego depletion paradigm) motivational deficits precipitate performance decrements (i.e., diminished self-control) on the second activity. For example, Inzlicht et al. (in press) contend that self-control's refractory period is the product of evolutionary pressures motivating people to balance their desires for exploitation versus exploration. This adaptive function translates further to a natural tendency to seek balance between externally rewarded labor and internally gratifying leisure. From this standpoint, self-control failure is less about resource depletion and more about the motivated switching of task priorities.

Importantly, the effort associated with acts of restraint in the real world (e.g., skipping dessert) may be mirrored during episodes of simulated self-control. Elsewhere, Morsella, Feinberg, Cigarchi, Newton, and Williams (2011) have shown that nonsense shapes are less desirable when

\footnotetext{
${ }^{3}$ Interestingly, Ackerman et al.'s (2009) story about the hungry waiter was written from a first-person perspective, thereby further underscoring the important role of vantage point during simulated self-control.
} 
associated with increasingly effortful processing experiences (i.e., $45^{\circ}$ to $135^{\circ}$ of mental rotation). Similarly, Botvinick and colleagues have demonstrated people's aversion to tasks and strategies that entail high levels of cognitive demand (Botvinick, 2007; Botvinick \& Rosen, 2009). Supporting the law of least mental effort, this research affirms that, like excessive physical activity, mental labor is disagreeable (Arai, 1912; Huxtable, White, \& McCartor, 1946). In the realm of simulated selfcontrol these findings suggest a potential pathway through which performance decrements may arise on the second of two sequential tasks. If, via sensorimotor re-enactment (Barsalou, 1999; Jeannerod, 1994; Moulton \& Kosslyn, 2009; Wilson, 2002) imaginary self-control elicits feelings of effort and negativity, then this may trigger motivational deficits that undermine subsequent restraint (Botvinick \& Rosen, 2009; Inzlicht \& Schmeichel, 2012; Inzlicht et al., in press). One useful task for future research will be to explore this possibility.

Notwithstanding the effects revealed herein, a caveat is in order. Despite the contention that imagined self-control can loosen subsequent restraint, in each of the reported experiments the outcome in question was a laboratory-based proxy for actual behavior. That is, participants never splashed real cash on designer shoes, stereotyped an actual person, or performed an adrenalinpumping parachute jump. In the extensive literature on ego depletion, however, prior periods of self-control have been shown to exert notable effects on an impressive range of everyday activities (Hagger et al., 2010). For example, when ego depleted, people are more likely to lie, cheat, eat, consume alcohol, smoke cigarettes, take unnecessary risks, and spend excessively on unplanned shopping trips (e.g., DeBono, Shmueli, \& Muraven, 2011; Freeman \& Muraven, 2010; Leeman, O’Malley, White, \& McKee, 2010; Muraven, Collins, \& Nienhaus, 2002; Vohs \& Faber, 2007; Vohs \& Heatherton, 2000). While the current findings are suggestive, it remains to be seen whether imagined restraint triggers comparable effects on non-imaginary outcomes. This issue awaits empirical investigation. 


\section{Conclusion}

The ability to control the self is an invaluable psychological skill (Muraven \& Baumeister, 2000). Through processes that foster inaction, people can avoid saying or doing the wrong thing. On occasion, however, this otherwise valuable skill can trigger surprising after effects - namely, lapses in restraint following periods of successful self-control (Hagger et al., 2010). Here we demonstrated comparable regulatory failings, but with two critical extensions: (i) self-control was imagined rather than actually performed; and (ii) such effects were only manifest under specific imagery conditions (i.e., concrete event representations). In so doing, the current findings further delineate how mental simulation impacts core aspects of social-cognitive functioning. 


\section{References}

Arai, T. (1912). Mental fatigue. Teachers College, Columbia University.

Ackerman, J.M., Goldstein, N.J., Shapiro, J.R., \& Bargh, J.A. (2009). You wear me out: The vicarious depletion of self-control. Psychological Science, 20, 326-332.

Addis, D.R., Wong, A.T., \& Schacter, D.L. (2007). Remembering the past and imagining the future: Common and distinct neural substrates during event construction and elaboration. Neuropsychologia, 45, 1363-1377.

Anderson, C.A. (1983). Imagination and expectation: The effect of imaging behavioral scripts on personal intentions. Journal of Personality and Social Psychology, 45, 293-305.

Avraamides, M., \& Kelly, J. (2008). Multiple systems of spatial memory and action. Cognitive Processing, 9, 93-106.

Barsalou, L.W. (1999). Perceptual symbol systems. Behavioral and Brain Sciences, 22, 577 660.

Baumeister, R.F., Bratslavsky, E., Muraven, M., \& Tice, D.M. (1998). Ego depletion: Is the active self a limited resource? Journal of Personality and Social Psychology, 74, 1252-1265.

Baumeister, R.F., Vohs, K.D., \& Tice, D.M. (2007). The strength model of self-control. Current Directions in Psychological Science, 16, 351-355.

Botvinick, M.M. (2007). Conflict monitoring and decision-making: Reconciling two perspectives on anterior cingulate function. Cognitive, Affective, \& Behavioral Neuroscience, 7, 356-366.

Botvinick, M.M., \& Rosen, Z.B. (2009). Anticipation of cognitive demand during decision-making. Psychological Research, 73, 835-842.

Boyer, P. (2008). Evolutionary economics of mental time travel? Trends in Cognitive Sciences, 12, 219-224.

Brouziyne, M., \& Molinaro, C. (2005). Mental imagery combined with physical practice of approach shots for golf beginners. Perceptual and Motor Skills, 101, 203-211. 
Buckner, R.L., \& Carroll, D.C. (2007). Self-projection and the brain. Trends in Cognitive Science, $11,49-57$.

Caliari, P. (2008). Enhancing forehand acquisition in table tennis: The role of mental practice. Journal of Applied Sport Psychology, 20, 88-96.

Christian, B.M., Miles, L.K., Fung, F.H.K., Best, S., \& Macrae, C.N. (2013). The shape of things to come: Exploring goal-directed prospection. Consciousness and Cognition, 22, 471-478.

Conway, M.A. (2010). Memory and the self. Journal of Memory and Language, 53, 594-628.

Conway, M.A., \& Pleydell-Pearce, C.W. (2000). The construction of autobiographical memories in the self-memory system. Psychological Review, 107, 261-288.

Decety, J., \& Grèzes, J. (2006). The power of simulation: Imagining one's own and other's behavior. Brain Research, 1079, 4-14.

Fadiga, L., \& Craighero, L. (2004). Electrophysiology of action representation. Journal of Clinical Neurophysiology, 21, 157-169.

Fischer, P., Guter, S., \& Frey, D. (2008). Risk-promoting media and risk-taking: The effects of risk promoting media on inclinations towards risk taking. Basic and Applied Social Psychology, $30,230-240$.

Fischer, P., Kastenmüller, A., \& Asal, K. (2012). Ego depletion increases risk-taking. The Journal of Social Psychology, 152, 623-638.

Freeman, N., \& Muraven, M. (2010). Self-control depletion leads to increased risk taking. Social Psychological and Personality Science, 1, 175-181.

Fujita, K., Henderson, M., Eng, J., Trope, Y., \& Liberman, N. (2006). Spatial distance and mental construal of social events. Psychological Science, 17, 278-282.

Fujita, K., Trope, Y., Liberman, N., \& Levin-Sagi, M. (2006). Construal levels and self-control. Journal of Personality and Social Psychology, 90, 351-367.

Gallese, V. (2005). Embodied simulation: From neurons to phenomenal experience. 
Gallese, V., Keysers, C., \& Rizzolati, G. (2004). A unifying view of the basis of social cognition. Trends in Cognitive Sciences, 8, 396-403.

Ganis, G., Thompson, W.L., \& Kosslyn, S.M. (2004). Brain areas underlying visual mental imagery and visual perception: An fMRI study. Cognitive Brain Research, 20, 226-241.

Gilbert, D.T., \& Wilson, T.D. (2007). Prospection: Experiencing the future. Science, 317, 13511354.

Glenberg, A.M. (2010). Embodiment as a unifying perspective for psychology. Wiley Interdisciplinary Reviews: Cognitive Science, 4, 586-596.

Goldman, A.I. (2006). Simulating minds: The philosophy, psychology and neuroscience of mindreading. New York: Oxford University Press.

Gordijn, E.H., Hindriks, I., Koomen, W., Dijksterhuis, A., \& Van Knippenberg, A. (2004). Consequences of stereotype suppression and internal suppression motivation: A selfregulation approach. Personality and Social Psychology Bulletin, 30, 212-224.

Govorun, O., \& Payne, B.K. (2006). Ego-depletion and prejudice: Separating automatic and controlled components. Social Cognition, 24, 111-136.

Grèzes, J., \& Decety, J. (2001). Functional anatomy of execution, mental simulation, observation and verb generation of actions: A meta-analysis. Human Brain Mapping, 12, 1-19.

Grouios, G. (1992). Mental practice: A review. Journal of Sport Behavior. 15, 42-59.

Hagger, M.S., Wood, C., Stiff, C., \& Chatzisarantis, N.L. (2010). Ego depletion and the strength model of self-control: A meta-analysis. Psychological Bulletin, 136, 495-525.

Heatherton, T. F., \& Vohs, K. (1998). Why is it so difficult to inhibit behavior? Psychological Inquiry, 9, 212-216.

Henderson, M.D., Wakslak, C.J., Fujita, K., \& Rohrbach, J. (2011). Construal level theory and spatial distance: Implications for mental representation, judgment, and behavior. Social Psychology, 42, 165-173. 
Holmes, E.A., \& Mathews, A. (2010). Mental imagery in emotion and emotional disorders. Clinical Psychology Review, 30, 349-362.

Huxtable, Z.L., White, M.H., \& McCartor, M.A. (1946). A re-performance and re-interpretation of the Aria experiment in mental fatigue with three subjects. Psychological Monographs, 59, 52.

Inzlicht, M., \& Schmeichel, B.J. (2012). What is ego depletion? Toward a mechanistic revision of the resource model of self-control. Perspectives on Psychological Science, 7, 450-463.

Inzlicht, M., Schmeichel, B.J., \& Macrae, C.N. (in press). Why self-control seems (but may not be) limited. Trends in Cognitive Sciences.

Jackson, P.L., Meltzoff, A.N., \& Decety, J. (2006). Neural circuits involved in imitation and perspective-taking. NeuroImage, 31, 429-439.

Jeannerod, M. (1994). The representing brain. Behavioral and Brain Sciences, 17, 187-245.

Jeannerod, M. (2001). Neural simulation of action: A unifying mechanism for motor cognition. NeuroImage, 14, 103-S109.

Killingsworth, M.A., \& Gilbert, D.T. (2010). A wandering mind is an unhappy mind. Science, $330,932$.

Kool, W., \& Botvinick, M. (in press). A labor/leisure tradeoff in cognitive control. Journal of Experimental Psychology: General.

Kosslyn, S.M., Ganis, G., \& Thompson, W.L. (2001). Neural foundations of imagery. Nature Reviews Neuroscience, 2, 635-642.

Kurzban, R., Duckworth, A., Kable, J.W., \& Myers, J. (2013). An opportunity cost model of subjective effort and task performance. Behavioral and Brain Sciences, 36, 661-679.

Landau, M.J., Meier, B.P., \& Keefer, L.A. (2010). A metaphor-enriched social cognition. Psychological Bulletin, 136, 1045-1067.

Leeman, R.F., O’Malley, S.S., White, M.A., \& McKee, S.A. (2010). Nicotine and food deprivation decrease the ability to resist smoking. Psychopharmacology, 212, 25-32. 
Libby, L.K., \& Eibach, R.P. (2011). Visual perspective in mental imagery: A representational tool that functions in judgment, emotion, and self-insight. Advances in Experimental Social Psychology, 44, 185-245.

Libby, L.K., Shaeffer, E.M., \& Eibach, R.P. (2009). Seeing meaning in action: A bidirectional link between visual perspective and action identification level. Journal of Experimental Psychology: General, 138, 503-516.

Liberman, N., \& Trope, Y. (2008). The psychology of transcending the here and now. Science, 322, 1201-1205.

Lorey, B., Bischoff, M., Pilgramm, S., Stark, R., Munzert, J., \& Zentgraf, K. (2009). The embodied nature of motor imagery: The influence of posture and perspective. Experimental Brain Research, 194, 233-243.

Macrae, C.N., Bodenhausen, G.V., Milne, A.B., \& Jetten, J. (1994). Out of mind but back in sight: Stereotypes on the rebound. Journal of Personality and Social Psychology, 67, 808-817.

Macrae, C.N., Sunder Raj, R., Best, S.B., Christina, B.M., \& Miles, L.K. (2013). Imagined sensory experiences can shape person perception: It's a matter of visual perspective. Journal of Experimental Social Psychology, 49, 595-598.

Mayer, J.D., \& Gaschke, Y.N. (1988). The experience and meta-experience of mood. Journal of Personality and Social Psychology, 55, 102-111.

McIssac, H.K., \& Eich, E. (2002). Vantage point in episodic memory. Psychonomic Bulletin \& Review, 9, 144-150.

McIssac, H.K., \& Eich, E. (2004). Vantage point in traumatic memory. Psychological Science, 15, $248-253$.

Meier, B.P., Schnall, S., Schwarz, N., \& Bargh, J.A. (2012). Embodiment in social psychology. Trends in Cognitive Sciences, 4, 705-716. 
Miles, L.K., Christian, B.M., Masilamani, N., Volpi, L., \& Macrae, C.N. (in press). Not so close encounters of the third kind: Visual perspective and imagined social interaction. Social Psychological and Personality Science.

Morsella, E., Feinberg, G.H., Cigarchi, S., Newton, J.W., \& Williams, L.E. (2011). Sources of avoidance motivation: Valence effects from physical effort and mental rotation. Motivation and Emotion, 35, 296-305.

Moulton, S.T., \& Kosslyn, S.M. (2009). Imagining predictions: Mental imagery as mental emulation. Philosophical Transactions of the Royal Society B, 364, 1273-1280.

Muraven, M. (2008). Prejudice as self-control failure. Journal of Applied Social Psychology, 38, 314-333.

Muraven, M., \& Baumeister, R.F. (2000). Self-regulation and the depletion of limited resources: Does self-control resemble a muscle? Psychological Bulletin, 126, 247-259.

Muraven, M., Collins, R.L., \& Nienhaus, K. (2002). Self-control and alcohol restraint: An initial application of the self-control strength model. Psychology of Addictive Behaviors, 16, 113120.

Prather, D.C. (1973). Prompted mental practice as flight simulator. Journal of Applied Psychology, $57,353-355$.

Ruby, P., \& Decety, J. (2001). Effect of subjective perspective taking during simulation of action: A PET investigation of agency. Nature Neuroscience, 4, 546-550.

Schacter, D.L., Addis, D.R., \& Buckner, R.L. (2007). Remembering the past to imagine the future: The prospective brain. Nature Reviews Neuroscience, 8, 657-661.

Smallwood, J., \& Schooler, J.W. (2006). The restless mind. Psychological Bulletin, 132, 946-958.

Solomon, R.L. (1948). The influence of work on behavior. Psychological Bulletin, 45, 1-40.

Suddendorf, T., \& Corballis, M.C. (2007). The evolution of foresight: What is mental time travel and is it unique to humans? Behavioral and Brain Sciences, 30, 299-351. 
Szpunar, K.K. (2010). Episodic future thought: An emerging concept. Perspectives on Psychological Science, 5, 142-162.

Taylor, S.E., Pham, L.B., Rivkin, I.D., \& Armor, D.A. (1998). Harnessing the imagination. American Psychologist, 53, 429-439.

Theiler, A.M. \& Lippman, L.G. (1995). Effects of mental practice and modelling on guitar and vocal performance. The Journal of General Psychology, 122, 329.

Thomas, M., \& Tsai, C.I. (2012). Psychological distance and subjective experience: How distancing reduces the feeling of difficulty. Journal of Consumer Research, 39, 324-340.

Trope, Y., Liberman, N. (2003). Temporal construal. Psychological Review, 110, 403-421.

Trope, Y., Liberman, N. (2013). Construal level theory of psychological distance. Psychological Review, 117, 440-463.

Vallacher, R.R., \& Wegner, D.M. (1985). A theory of action identification. Hillsdale, NJ: Erlbaum.

Vohs, K.D., \& Faber, R.J. (2007). Spent resources: Self-regulatory resource availability affects impulse buying. Journal of Consumer Research, 33, 537-547.

Vohs, K.D., \& Heatherton, T.F. (2000). Self-regulatory failure: A resource-depletion approach. Psychological Science, 11, 243-254.

Vyse, S.A. (2000). Believing in magic: The psychology of superstition. New York: Oxford University Press.

Wegner, D.M. (1994). Ironic processes of mental control. Psychological Review, 101, 34-52.

Wheeler, S.C., DeMarree, K.G., \& Petty, R.E. (2007). Understanding the role of the self in primeto-behavior effects: The active-self account. Personality and Social Psychology Review, 11, 234-261.

Wilson, M. (2002). Six views of embodied cognition. Psychonomic Bulletin and Review, 9, 625-636.

Woolfolk, R.L., Parrish, M.W. \& Murphy, S.M. (1985). The effects of positive and negative imagery on motor skill performance. Cognitive Therapy and Research, 9, 335-341. 
Zuckerman, M. (1971). Dimensions of sensation seeking. Journal of Consulting and Clinical Psychology, 36, 45-52. 


\section{Acknowledgements}

The authors thank Michael Inzlicht, Roy Baumeister and two anonymous reviewers for their helpful comments on this work. Correspondence concerning the article should be directed to Neil Macrae at c.n.macrae@abdn.ac.uk. 


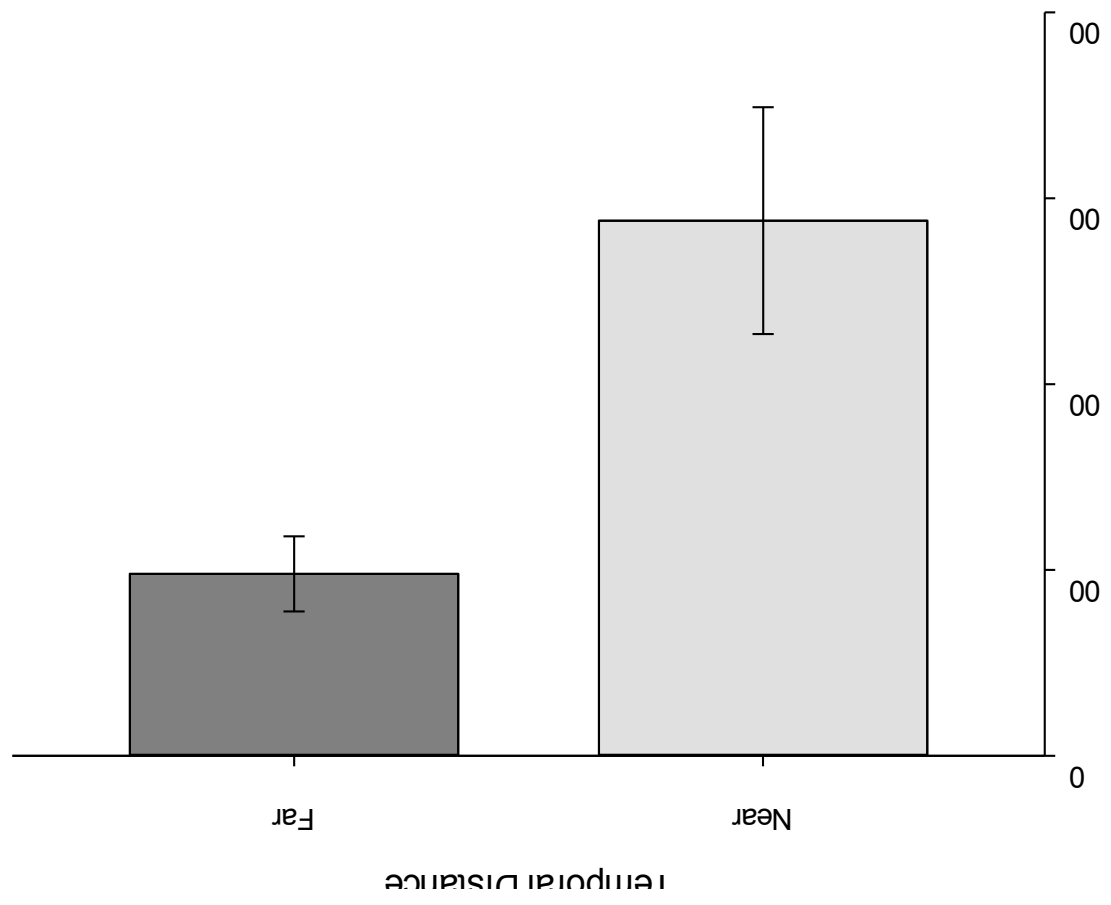

Figure 1: Mean amount spent in price-assignment task as a function of temporal distance (i.e., near vs. far future) of imaginary event. Error bars represent \pm 1 SEM. 


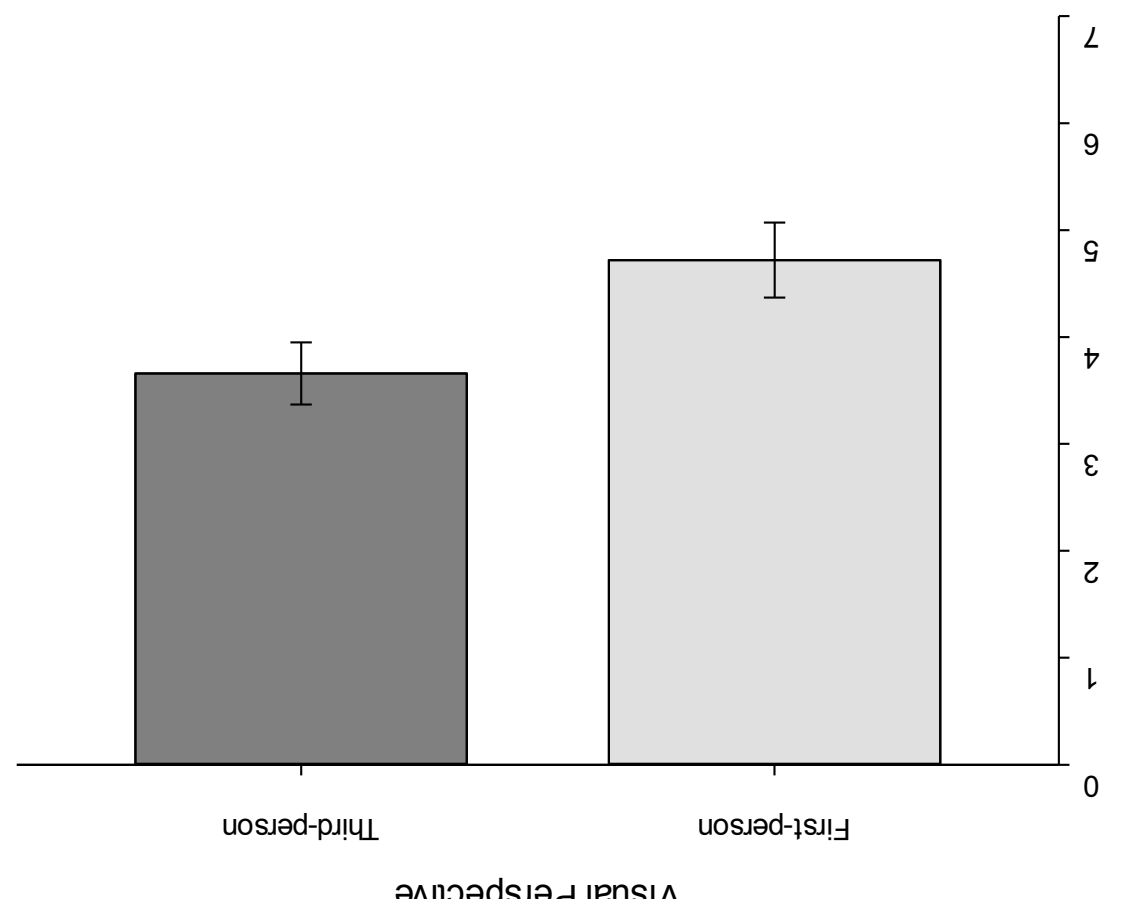

Figure 2: Mean ratings of stereotypical content $(1=$ not at all stereotypic; $7=$ highly stereotypic $)$ as a function of the visual perspective (i.e., first- vs. third-person) adopted during the imaginary event. Error bars represent \pm 1 SEM. 


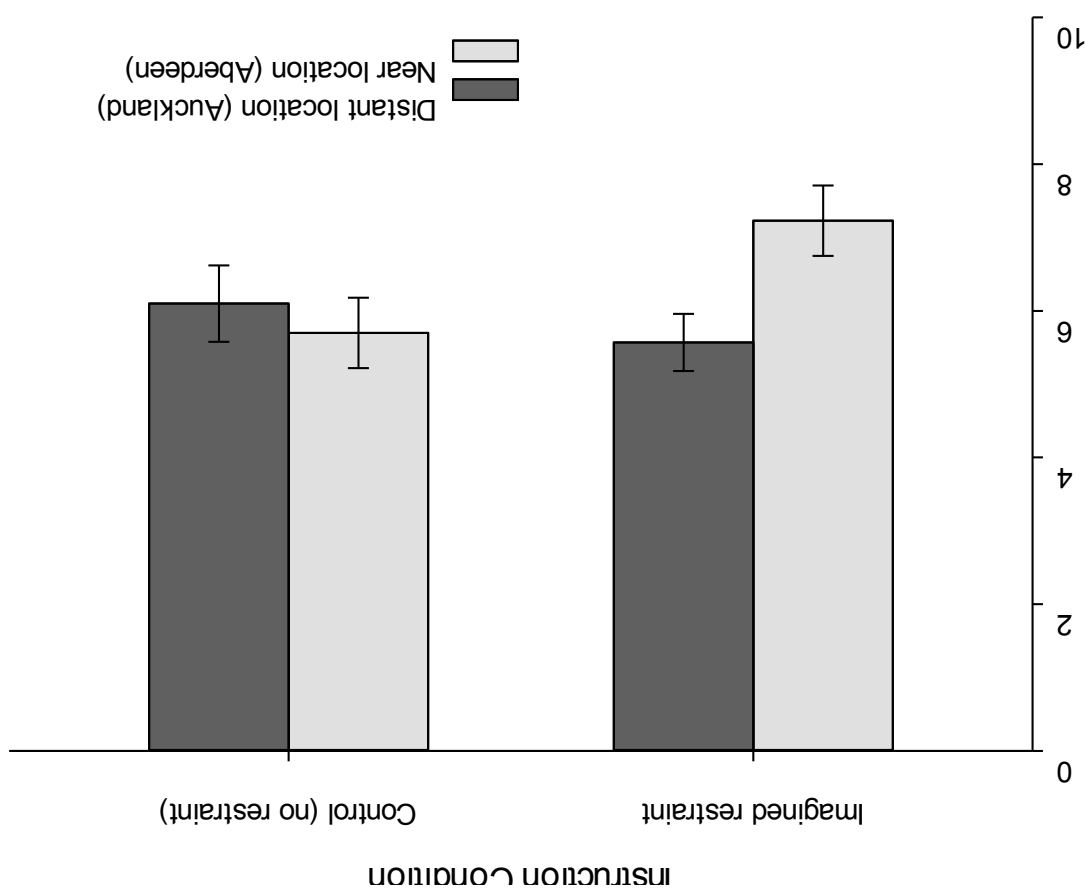

Figure 3: Mean thrill-seeking score (higher scores = more thrill-seeking) as a function of instruction condition (i.e., imagined restraint vs. control) and location (i.e., near vs. distant) of the imaginary event. Error bars represent \pm 1 SEM. 